\title{
Optical spectroscopic characterizations of laser irradiated olivine grains (Corrigendum)
}

\author{
Yazhou Yang $(\text { 杨亚洲 })^{1}$, Hao Zhang (张昊 $)^{1,2}$, Ziwei Wang (王紫薇 $)^{1}$, Ye Yuan (袁野) ${ }^{1}$, \\ Shaolin Li (李少林) $)^{3}$, Weibiao Hsu (徐伟彪) $)^{3}$, and Chujian Liu (刘初见 $)^{4}$ \\ ${ }^{1}$ Planetary Science Institute, School of Earth Sciences, China University of Geosciences, 430074 Wuhan, PR China \\ e-mail: um_zhanghao@yahoo.com; yangyazhou1@gmail.com \\ ${ }^{2}$ Key Laboratory of Spectral Imaging Technology, Xi' an Institute of Optics and Precision Mechanics, Chinese Academy of Sciences, \\ 710119 Xi' an, PR China \\ ${ }^{3}$ Purple Mountain Observatory, Chinese Academy of Sciences, Nanjing, PR China \\ ${ }^{4}$ State Key Laboratory of Geological Process and Mineral Resources, China University of Geosciences, Wuhan, PR China
}

A\&A, 597, A50 (2017), https://doi .org/10.1051/0004-6361/201629327

Key words. methods: laboratory: solid state - techniques: spectroscopic - radiative transfer - infrared: general planets and satellites: surfaces - errata, addenda

This is a corrigendum to Yang et al. (2017). There is a typo in the Fo (Mg-number) of the olivine sample. The Fo is defined as the molar ratio of $\mathrm{Mg} /(\mathrm{Mg}+\mathrm{Fe})$. The chemical composition values listed in Table 1 are correct, but the calculated Fo\# value should be 91 . This has no effect on our results or conclusions. The revised table and paragraph are given below, with the revised parts highlighted in bold.

\section{Materials and methods}

\subsection{Experimental procedure}

Samples. Olivine, a common mineral found in many meteorites and S-type asteroids (e.g., Chapman 1996, 2004), was used as the analog material in this work. Natural pure olivine granules collected from Hebei Province, China, were first ground into a size distribution of $0-75 \mu \mathrm{m}$ with a vibratory disc mill (VDM). The olivine powders were then sieved and those smaller than $45 \mu \mathrm{m}$ were separated out as the target sample. The chemical compositions of these olivine powders were analyzed using the wet chemistry method. To ensure that no contaminations were introduced during the grinding process, compositional measurements were made on both the original samples and the powders processed with the VDM. The major element contents of these two samples, as summarized in Table 1, indicate that the grinding process did not introduce any contaminations of iron, and the $\mathrm{Mg}$ number of the olivine sample is 91 (Fo91).
Table 1. Chemical composition of the original and the VDM processed olivine samples.

\begin{tabular}{|c|c|c|}
\hline $\begin{array}{l}\text { Major } \\
\text { elements }\end{array}$ & $\begin{array}{l}\text { Original olivine } \\
\text { (wt. \%) }\end{array}$ & $\begin{array}{c}\text { Olivine processed } \\
\text { with VDM (wt. \%) }\end{array}$ \\
\hline $\mathrm{SiO}_{2}$ & 40.660 & 40.980 \\
\hline $\mathrm{Al}_{2} \mathrm{O}_{3}$ & 0.340 & 0.230 \\
\hline $\mathrm{TFe}_{2} \mathrm{O}_{3}{ }^{(*)}$ & 9.760 & 9.780 \\
\hline $\mathrm{MgO}$ & 48.000 & 48.590 \\
\hline $\mathrm{CaO}$ & 0.056 & 0.042 \\
\hline $\mathrm{Na}_{2} \mathrm{O}$ & 0.008 & 0.010 \\
\hline $\mathrm{K}_{2} \mathrm{O}$ & 0.004 & 0.003 \\
\hline $\mathrm{TiO}_{2}$ & 0.011 & 0.005 \\
\hline $\mathrm{P}_{2} \mathrm{O}_{3}$ & 0.005 & 0.012 \\
\hline $\mathrm{MnO}$ & 0.110 & 0.110 \\
\hline $\mathrm{H}_{2} \mathrm{O}$ & 0.040 & 0.040 \\
\hline Total & 98.994 & 99.802 \\
\hline $\mathrm{Fo \#}{ }^{(* *)}$ & 91 & 91 \\
\hline
\end{tabular}

Notes. ${ }^{(*)}$ Total iron; ${ }^{(* *)} \mathrm{Mg}$-number.

\section{References}

Chapman, C. R. 1996, Meteorit. Planet. Sci., 31, 699

Chapman, C. R. 2004, Annu. Rev. Earth Planet. Sci., 32, 539

Yang, Y., Zhang, H., Wang, Z., et al. 2017, A\&A, 597, A50 